\title{
Through the Lens of Scientific Racism: Patient Race Should Not Be Included in the Oral Presentation
}

\author{
Pallavi Juneja ${ }^{1}$ (1) \\ Accepted: 11 May 2021 / Published online: 18 May 2021 \\ (c) International Association of Medical Science Educators 2021
}

\begin{abstract}
Medical students are taught to include the patient demographics of age and gender in the oral presentation; the inclusion of race is controversial. Epidemiology demonstrates that race, as a social determinant of health, can be a risk factor for disease. However, race, as a social construct, is not a biological cause for disease. In the USA, the relationship between race and health is stained by a long history of scientific racism, and the misuse of science does not rest in our past. Given the complexity and persistence of scientific racism, race should not be included in the oral presentation.
\end{abstract}

For the sake of consistency and clarity-two critical values in medicine-all patient presentations begin with a oneliner. Something like, "Mr. A is a 56-year-old man with a history of coronary artery disease who presents with chest pain." As a medical student, putting together the first line is usually the easiest part. Learning how to give the rest of the oral presentation, however, is a difficult lesson because it requires a delicate balance between being concise as well as complete. Early in our training, we don't always know what is pertinent to include, so we often err on the side of oversharing. Nonetheless, we try over and over again throughout third and fourth year to distill each patient's demographics and medical history into a concise story that tells the attending everything she needs to know-no more, no less.

During my third year of medical school, even the opening line got complicated: I worked with a physician who required the race of the patient to be included in my oneliner. Foremost, the question of how patient race should be determined is problematic [1]. But assuming that race could be accurately ascertained, I understood her request to mean that race was pertinent information to her medical decisionmaking. In my brief experience on the wards, this is not common but is also not unheard of.

The physician was a woman of color. Knowing that people of all backgrounds demonstrate implicit bias but Black physicians demonstrate less racial bias, I instinctively felt

Pallavi Juneja

pjuneja@wakehealth.edu

1 Wake Forest School of Medicine, Winston Salem, NC 27101, USA just a little bit less uncomfortable [2]. Still, I was surprised. Of course, disease prevalence does vary by race. From a public health perspective, race can be considered a "risk factor." Such logic is one reason we include age of the patient (e.g., chest pain in a 56-year-old man is categorically not the same as chest pain in a 6-year-old boy). But using public health information and aggregate data to frame individual patients also carries the risk of "anchoring."

In medical practice, anchoring is a cognitive error where the physician depends too heavily on an initial piece of information (like race) when making a decision. For example, I recently witnessed a physician misdiagnose a patient-an error that appeared to be driven, in part, by assumptions given the patient's race. A young African American single mother living in a mobile home who presented with myoclonic jerks was presumed to be in drug withdrawal despite a negative urine drug screen and no history of drug use. The association between race and drug use may seem clear given the much higher rates of incarceration among African Americans for drug-related crimes [3]. However, this apparent association is only a consequence of systemic racism pervading our carceral system: drug use is actually the same by percentage of population among White Americans and Black Americans [3]. Ultimately, the patient was diagnosed with an autoimmune epilepsy.

But in medical test-taking, the error of anchoring is sometimes rewarded. Our board exams are $9 \mathrm{~h}$ long and timed so that we cannot spend more than $90 \mathrm{~s}$ per question. We are encouraged to find anchors to make a diagnosis quickly, then move on. In the land of multiple choice, the patient's race can be vital. For example, when I read, "Ms. A is a 
33-year-old African American female who presents with a cough," I immediately consider a rare disease like sarcoidosis only because the patient is Black.

So where do we draw the line? While drug use does not vary by race, sarcoidosis is more likely in African Americans [4]. Other diseases, like cystic fibrosis, are more common in Caucasians [5]. And some common diseases disproportionately affect certain races. For example, the CDC tell us that African Americans ages 18-49 are two times more likely to die from heart disease than Whites [6].

In order to investigate whether race is pertinent enough to include in the oral presentation, let us consider a different question: can race cause disease?

A teaching in epidemiology, known as the Bradford Hill criteria, offers nine guidelines that should be considered when inferring causality [7]. Most of the guidelines rely on population data. But two-coherence and biologic plausibility-require scientific evidence instead. For one, if race is to be considered a "cause" of disease, then biologic science must show that race can plausibly cause disease. And secondly, coherence between biology and population trends-as well as lack of contradiction-will strengthen the causal relationship.

Using this approach to causality, the question quickly becomes: is there a scientific reason that race might cause disease? With mapping of the entire human genome available and the new goals of precision medicine, this question can be exciting in our current moment. But the renewed interest in genetics cannot erase the fact that race is a social construct rather than a biological truth [8]. Consider the diversity of patients that are placed together under artificial labels like 'Black' or 'Hispanic'; it becomes clear that race does not have clear borders in society or scientifically. In fact, there is objective evidence that racial groups are not defined by distinct and unifying genetic codes [9]. The renewed interest in genetics also cannot erase the many attempts (past and present) to falsely claim that race is a simple biological assignment-claims that have buoyed a long history of scientific racism in the USA.

For example, in March 1851, a physician named Samuel A. Cartwright introduced a new disease to the Medical Association of Louisiana: drapetomania (drapetes, a runaway, and mania, madness) [10]. He explained that this malady was affecting slaves in the South, causing them to flee their owners. He called upon the evidence of "Negroes' smaller brains and blood vessels" to make his case. Basically, he used "science" to diminish a human desire for freedom into a disease that only reinforced Black social inferiority. That same year, Josiah C. Nott, a physician and future medical director of the Confederate Army, presented the following evidence to the Southern Rights Association about slaves: "Their physical type is peculiar; their grade of intellect is greatly inferior; they are utterly wanting in moral and physical energy" [11].
Dr. Nott's presentation exceeds common and deplorable racism; as a physician, he was offering scientific validity for racism.

Such scientific racism birthed eugenics, the hateful halfcousin of Darwin's natural selection (actually created by Darwin's half-cousin, Francis Galton). Eugenics 'arranges' reproduction to propagate 'desirable' characteristics [12]. In 1896, Connecticut made it illegal for people with epilepsy to marry [12]. In 1927, the Supreme Court actually permitted sterilization of the "unfit" (a decision which has not ever been expressly overturned). In 70 years, between 1909 and 1979, around 20,000 sterilizations were performed in the mental institutions of California alone [12]. Science, revered for being objective and factual, has been used over and over again to not only justify but also encourage racism as well as sexism and ableism and homophobia and other modes of hate.

But this isn't a thing of the past. Scientific racism also hides within the names that we still know and respect. In the nineteenth century, Dr. John Downs, after whom Downs Syndrome is named, first used the term "Mongolian idiocy" to describe children with Trisomy 21 [13]. He coined this term because he felt that the physical features resembled "Mongolian races." The name was only switched to Downs Syndrome after four geneticists wrote a letter published by Lancet in 1961: "The importance of this anomaly among Europeans and their descendants is not related to the segregation of genes derived from Asians...We urge, therefore, that the expressions which imply a racial aspect of the condition be no longer used" [14].

All of this to say, non-specific catchalls, like 'Black,' simply cannot be the biological cause of heart disease. Thus, the inclusion of a patient's race in the oral presentation is biologically unhelpful—neither a pertinent positive nor a pertinent negative.

Still, as an epidemiologic risk factor, patient race might be helpful to medical decision-making, particularly in disease processes like sarcoidosis or cystic fibrosis. However, once we acknowledge the long and persistent history of scientific racism in our country, the inclusion of a patient's race is not only unhelpful but might actually be harmful instead. In a future world that hopefully eradicates racism, the balance between helpful and harmful might tip differently.

Now, amidst a global pandemic, the intersection of race and science is more relevant than ever. Specifically, in the USA, COVID-19 is tearing through the Black community. US Surgeon General Jerome Adams offered as clear an explanation as any: "We do not think people of color are biologically or genetically disposed to get COVID-19, but they are socially predisposed to coronavirus exposure" [15].

$\mathrm{He}$ is telling us something that we already know and describe as social determinants of health. For one, many of our "essential" service-oriented jobs are filled by Black 
Americans, making social isolation hard [16]. Secondly, more Black Americans use public transportation regularly and less Black Americans own their own home, making social isolation harder $[17,18]$. Plus, Black Americans are sicker at baseline-for example, with higher rates of asthma-in part because of environmental exposures, making them more likely to be sicker if infected [19]. And finally, Black people are not only less likely to trust doctors (known informally as the Tuskegee effect, named after the horribly unethical experiment spanning 1932-1972) but are also more likely to face hidden biases to care, making treatment more difficult to obtain [20,21].

The fact that our Surgeon General had to directly address scientific racism is concerning though perhaps unsurprising. The pandemic has forced us all to learn about public health. And some folks are doing less learning and more discriminating. For example, anti-Asian xenophobia is common enough that the CDC had to officially comment on it [22]. And rumblings that older people should sacrifice themselves for the economy are eugenics all over again: an unsettling suggestion that frailty is 'undesirable' so perhaps we ought to give natural selection a boost.

But, if Black people are "socially predisposed" to COVID-19, then race does matter, right?

Yes. Even if race is only a proxy for systemic racism, this is often the source of epidemiological risk. So, we cannot claim to be "color-blind." To this end, physicians might argue that knowing a patient's race up front is appropriate. In addition, some think that it helps them better remember the patient; others suggest that it is a cognitive forcing strategy that ultimately aids in debiasing. But the former coalesces personhood and race, even if only unconsciously, and the latter is inconsistently proven, perhaps due to its simplification of cognitive processing [23].

So, given that race matters in health care disparities, should trainees include race in oral presentations?

No. It might be relevant to medical decision-making, if not biologically, then epidemiologically or perhaps in what it might indicate about a patient's social circumstances. But race is too complex to be used as a proxy for social factors or as a primary frame for diagnostic thinking. And the history of scientific racism is too haunting and too persistent to overlook; after all, racial disparities in pain assessment and treatment on the basis of biological myth were uncovered just 4 years ago [24]. Thus, while race is decidedly not a simple biological truth, physicians ought not use race as a way to assume social determinants of health either; instead, we must gather a thorough social history as needed.

Ultimately, we cannot allow the promise of objective science- the same science that Samuel Cartwright used-flatten social determinants of health into biological myths about race. We must acknowledge that, in the USA, the relationship between race and health is stained by a long history of scientific racism, and the misuse of science does not rest in our past. So as we continue to train and are inundated with information about the intersection of science and race, let us be vigilant about avoiding scientific racism. And as medical schools confront how they teach race and its history in medicine, let us keep race out of the oral presentation. It isn't pertinent and it isn't worth it.

\section{Declarations}

Ethics Approval This is a commentary; as a result, no ethical approval was required.

Conflict of Interest The authors declare no competing interests.

\section{References}

1. Acquaviva KD, Mintz M. Perspective: are we teaching racial profiling? The dangers of subjective determinations of race and ethnicity in case presentations. Acad Med. 2010;85(4):702-5. https:// doi.org/10.1097/ACM.0b013e3181d296c7 (PMID: 20354391).

2. Chapman EN, Kaatz A, Carnes M. Physicians and implicit bias: how doctors may unwittingly perpetuate health care disparities. J Gen Intern Med. 2013;28(11):1504-10. https://doi.org/10.1007/ s11606-013-2441-1.

3. Rates of drug use and sales, by race; rates of drug related criminal justice measures, by Race. (2020, October 08). Retrieved November 12, 2020, from https://www.hamiltonproject.org/charts/ rates_of_drug_use_and_sales_by_race_rates_of_drug_related_ criminal_justice

4. Mirsaeidi M, Machado RF, Schraufnagel D, Sweiss NJ, Baughman RP. Racial difference in sarcoidosis mortality in the United States. Chest. 2015;147(2):438-49.

5. Cystic fibrosis - Genetics Home Reference - NIH. (2020, August 17). Retrieved September 05, 2020. https://ghr.nlm.nih.gov/condition/ cystic-fibrosis

6. African American Health. (2017, July 03). Retrieved September 05, 2020. https://www.cdc.gov/vitalsigns/aahealth/index.html

7. Fedak KM, Bernal A, Capshaw ZA, Gross S. Applying the Bradford Hill criteria in the 21st century: how data integration has changed causal inference in molecular epidemiology. Emerg Themes Epidemiol. 2015;12:14.

8. Gannon M. Race is a social construct, scientists argue. Scientific American. 2016 Feb 5;5. Available from: https://www.scientificamerican. com/article/race-is-a-social-construct-scientists-argue/

9. Rosenberg NA, Pritchard JK, Weber JL, et al. Genetic structure of human populations. Science. 2002;298(5602):2381-5.

10. Ruane M. A brief history of the enduring phony science that perpetuates white supremacy. Washington Post [newspaper on the Internet]. 2019 April 30 [cited 2020 Sept 05]; Local. Available from: https://www.washingtonpost.com/local/a-brief-history-ofthe-enduring-phony-science-that-perpetuates-white-supremacy/ 2019/04/29/20e6aef0-5aeb-11e9-a00e-050dc7b82693_story.html

11. DenHoed A, Lepore J, Press E, Mahajan K. The Forgotten Lessons of the American Eugenics Movement. The New Yorker [magazine on the Internet]. 2017 April 17 [cited 2020 Sept 05]; Books. Available from: https://www.newyorker.com/books/pageturner/the-forgotten-lessons-of-the-american-eugenics-movement 
12. Eugenics. (2017, November 15). Retrieved September 05, 2020. https://www.history.com/topics/germany/eugenics

13. Van Robays J. John Langdon Down (1828-1896). Facts Views Vis Obgyn. 2016;8(2):131-6.

14. Allen G, Benda CE, Böök JA, et al. Mongolism. Am J Hum Genet. 1961;13(4):426.

15. Haltiwanger J. Surgeon General says people of color are getting hit harder by coronavirus because of social issues, not genetics or biology. Business Insider [magazine on the Internet]. 2020 April 10 [cited 2020 Sept 05]; Politics. Available from: https://www. businessinsider.com/surgeon-general-people-of-color-vulnerablecoronavirus-social-issues-2020-4

16. Cerullo M. Black and Hispanic workers less able to work from home. CBS News [available on the Internet]. 2020 May 21 [cited 2020 Sept 05]; Money Watch. Available from: https://www.cbsnews.com/news/ work-from-home-black-hispanic-workers/

17. Anderson M. Who relies on public transit in the U.S. Pew Research Center [available on the Internet]. 2020 May 30 [cited 2020 Sept 05]. Available from: https://www.pewresearch.org/facttank/2016/04/07/who-relies-on-public-transit-in-the-u-s/

18. Quarterly residential vacancies and homeownership, second quarter 2020. U.S. census Bureau [available on the Internet]. 2020 July 28 [cited 05 Sept 2020]. Available from: https://www.census.gov/ housing/hvs/files/currenthvspress.pdf

19. Ethnic disparities in the burden and treatment of asthma. Retrieved September 05, 2020. https://www.aafa.org/media/1633/ethnicdisparities-burden-treatment-asthma-report.pdf
20. Newkirk II, VR. An unethical medical study took a year off the lives of black men. The atlantic [magazine on the Internet]. 2016, June 17 [cited 2020 Sept 05]; Politics. Availalbe from: https:// www.theatlantic.com/politics/archive/2016/06/tuskegee-studymedical-distrust-research/487439/

21. Gupta S. Bias in a common health care algorithm disproportionately hurts black patients. Science News [available on the Internet]. 2019 Nov 09; cited 2020 Sept 05]. Available from: https://www.sciencenews.org/article/bias-common-health-carealgorithm-hurts-black-patients

22. Reducing Stigma. (2020, June 11). Retrieved September 05, 2020. https://www.cdc.gov/coronavirus/2019-ncov/daily-life-coping/ reducing-stigma.html

23. Oliver G, Oliver G, Body R. BET 2: Poor evidence on whether teaching cognitive debiasing, or cognitive forcing strategies, lead to a reduction in errors attributable to cognition in emergency medicine students or doctors. Emerg Med J. 2017;34(8):553-4. https:// doi.org/10.1136/emermed-2017-206976.2 (PMID: 28724568).

24. Hoffman KM, Trawalter S, Axt JR, Oliver MN. Racial bias in pain assessment and treatment recommendations, and false beliefs about biological differences between blacks and whites. Proc Natl Acad Sci USA. 2016;113(16):4296-301.

Publisher's Note Springer Nature remains neutral with regard to jurisdictional claims in published maps and institutional affiliations. 